\title{
Autism and chronic ill health: an observational study of symptoms and diagnoses of central sensitivity syndromes in autistic adults
}

Sarah Grant ${ }^{1^{*} \mathbb{D}}$, Sam Norton', Ricarda F. Weiland ${ }^{2}$, Anke M. Scheeren ${ }^{2}$, Sander Begeer ${ }^{2}$ and Rosa A. Hoekstra ${ }^{1}$

\begin{abstract}
Background: Autistic adults, particularly women, are more likely to experience chronic ill health than the general population. Central sensitivity syndromes (CSS) are a group of related conditions that are thought to include an underlying sensitisation of the central nervous system; heightened sensory sensitivity is a common feature. Anecdotal evidence suggests autistic adults may be more prone to developing a CSS. This study aimed to investigate the occurrence of CSS diagnoses and symptoms in autistic adults, and to explore whether CSS symptoms were related to autistic traits, mental health, sensory sensitivity, or gender.
\end{abstract}

Methods: The full sample of participants included 973 autistic adults (410 men, 563 women, mean age $=44.6$ ) registered at the Netherlands Autism Register, who completed questionnaires assessing autistic traits, sensory sensitivity, CSS, physical and mental health symptoms. The reliability and validity of the Central Sensitization Inventory (CSI) in an autistic sample was established using exploratory and confirmatory factor analyses. Chi ${ }^{2}$ analyses, independent $t$-tests, hierarchical regression and path analysis were used to analyse relationships between CSS symptoms, autistic traits, measures of mental health and wellbeing, sensory sensitivity, age and gender.

Results: $21 \%$ of participants reported one or more CSS diagnosis, and $60 \%$ scored at or above the clinical cut-off for a CSS. Autistic women were more likely to report a CSS diagnosis and experienced more CSS symptoms than men. Sensory sensitivity, anxiety, age and gender were significant predictors of CSS symptoms, with sensory sensitivity and anxiety fully mediating the relationship between autistic traits and CSS symptoms.

Limitations: Although this study included a large sample of autistic adults, we did not have a control group or a CSS only group. We also could not include a non-binary group due to lack of statistical power.

Conclusions: CSS diagnoses and symptoms appear to be very common in the autistic population. Increased awareness of an association between autism and central sensitisation should inform clinicians and guide diagnostic practice, particularly for women where CSS are common and autism under recognised.

Keywords: Autism, Central sensitisation, Sensory processing, Sensory sensitivity, Fibromyalgia, Fatigue, Chronic pain

*Correspondence: sarah.grant@kcl.ac.uk

1 Department of Psychology, Institute of Psychiatry, Psychology and Neuroscience, King's College London, London SE5 8AF, UK

Full list of author information is available at the end of the article

\section{Background}

Autistic people are more likely to experience a broad range of physical health issues [1], including chronic disease and premature mortality $[2,3]$ and have poorer general health outcomes [4] than the wider population. original author(s) and the source, provide a link to the Creative Commons licence, and indicate if changes were made. The images or other third party material in this article are included in the article's Creative Commons licence, unless indicated otherwise in a credit line to the material. If material is not included in the article's Creative Commons licence and your intended use is not permitted by statutory regulation or exceeds the permitted use, you will need to obtain permission directly from the copyright holder. To view a copy of this licence, visit http://creativecommons.org/licenses/by/4.0/. The Creative Commons Public Domain Dedication waiver (http://creativeco mmons.org/publicdomain/zero/1.0/) applies to the data made available in this article, unless otherwise stated in a credit line to the data. 
However, the underlying mechanisms are not yet well established. One group of physical problems colloquially thought to be more prevalent in autistic people are 'central sensitivity syndromes' (CSS) including myalgic encephalomyelitis/chronic fatigue syndrome (ME/CFS), fibromyalgia syndrome (FMS), migraine, irritable bowel syndrome (IBS) restless legs syndrome (RLS) and temporomandibular joint disorder (TMJD). CSS are thought to have central sensitisation, or augmented sensory signalling of the central nervous system, as a core component [5]; symptoms include fatigue, chronic pain and sensory hypersensitivity. In the general population, prevalence estimates of CSS vary $0.2-20 \%$ [6-12] depending on type of syndrome and country. For example, fibromyalgia is thought to be prevalent at between 0.2 and $6.6 \%$ in the general population [6], but the global prevalence for IBS has been more difficult to ascertain, with ranges varying from $5.8 \%$ in the Middle East and Africa, up to $17.5 \%$ in Latin America [10].

A core feature common to both autism [13] and CSS [14] is sensory sensitivity. While sensory research in autism has been more focussed on altered experience and heightened sensory sensitivity across all modalities [15], CSS research has been centred around pain [16]. Therefore, whilst CSS studies have acknowledged that general sensory sensitivity, and not just pain, is part of central sensitisation [17-21], the mechanisms of individual differences in sensory sensitivity within this population, as well as the neurodivergent and general population, are still unclear [22]. Studies on sensory differences in autism are plentiful $[13,15,23,24]$ but research specifically on the autistic pain experience is more limited. Research on acute pain in autism, and quantitative sensory testing studies, has suggested that autistic people have a normal or hypersensitive physiological response to acute pain, but may express pain differently [25-28] and also experience more pain-related anxiety [29], but it has not yet been established whether this anxiety contributes to, or is caused by, altered pain sensitivity. Neural differences in the sustained pain response have also been found in autistic people [30] but to date there have been no studies exploring the phenomenon of central sensitisation in the autistic population.

Sensory sensitivity is not the only commonality between autism and CSS. The autistic and CSS communities both experience psychosocial factors that can reduce their physical and mental wellbeing, including (but not limited to) poor mental health [31-33], trauma [34, 35], stigma and discrimination [36-39], socioeconomic disparity $[40,41]$ and poor access to or experiences with healthcare [42, 43]. CSS have a troubled history in the research literature, with many clinicians still referring to them as somatoform disorders despite considerable evidence to the contrary [44, 45]. Psychosocial factors have been shown to play a complex role in the development and maintenance of CSS and chronic pain [46] however how these factors affect physical health in the autistic community is under-explored.

Research looking directly at an association between autism and CSS is limited. Paediatric studies have highlighted a higher incidence of neurodevelopmental disorders in children with chronic pain $[47,48]$ and/or CSS $[49,50]$, but there is little equivalent research in adults. There is, however, growing awareness of a link between autism and genetic connective tissue disorders, particularly joint hypermobility- related disorders [51, 52] and the Ehlers-Danlos syndromes [53]. These conditions often co-occur with CSS [54-56], but more research is needed to determine whether this directly translates to an association between autism and CSS.

CSS are much more commonly diagnosed in women than in men [57]. Women are also proposed to have greater pain sensitivity [58, 59] and heightened central sensitisation [60] although how much of this difference is truly gender specific [61] and how much can be attributed to gender bias $[62,63]$ is unclear. Gender is also an important predictor of an autism diagnosis and physical health in autism. Autism has historically been under recognised [64] and diagnosed later [65] in women, and autistic women appear to experience a greater range of co-occurring physical conditions than autistic men [66]. Whether CSS are more common in autistic women has not been explored.

Our study aimed to investigate the rates of CSS and CSS symptoms in a sample of autistic adults. We first examined the dimensionality and reliability of the Central Sensitization Inventory (CSI), a widely used CSS measure [67], in this autistic sample. We hypothesized that, given the link between autism and sensory sensitivity, and sensory sensitivity and central sensitisation, as well as the high incidence of co-occurring conditions in autism, CSS symptoms would be common in autistic adults and may be more prevalent than observed in the general population. We also hypothesized that, since high scores on measures of autistic traits correlate with autism diagnoses [68], then autistic traits would be positively associated with CSS symptoms as measured through the CSI.

We also postulated that higher CSI scores would be associated with greater sensory sensitivity, higher anxiety and depression scores and poorer physical health and subjective well-being, and we predicted that autistic women would report greater sensory sensitivity and more CSS symptoms than autistic men. Lastly, as sensory sensitivity, anxiety and chronic pain have been linked together in previous studies $[29,69]$ we considered 
whether sensory sensitivity or anxiety might mediate a relationship between autism and CSS.

\section{Methods \\ Participants}

The sample comprised 973 adults (410 men, 563 women) all of whom had been formally diagnosed with autism. Nine people who indicated their gender was "other" were excluded due to the small sample size.

The mean age of the sample was 44.6 years $(\mathrm{SD}=13.58)$, with men $($ Mean $=48.7, \mathrm{SD}=13.42)$ significantly older than women (Mean $=41.7, \mathrm{SD}=12.93, p<0.001)$. One participant had not confirmed their age. $18.6 \%$ of the sample had completed a university degree, $21.5 \%$ a higher professional education, $16.3 \%$ a vocational education, $20.6 \%$ had another type of education and $23.0 \%$ had not specified their level of education. Participants were asked about ethnicity, and the vast majority indicated Dutch heritage, with only $2 \%$ indicating non-Western heritage either through their own or their parents' country of origin.

Participants were recruited through the Netherlands Autism Register (NAR www.nederland- sautismeregister.nl/english/), a longitudinal autism research volunteer register that is administered on an annual basis to autistic people and/or their legal representatives. The data collection for this study was self-report and was part of an ongoing wave of NAR surveys. Due to the nature of the NAR, some questionnaires in this study have a greater number of participants than others; for example, the SPQ was completed in 2016 when the NAR had fewer participants than in 2019 when the CSI was completed. For this study, participants were asked questions as part of the overall survey rather than being specifically recruited, ensuring we minimised bias in the recruitment process.

\section{Measures \\ Central sensitisation}

The Central Sensitization Inventory [70] was developed as a valid and reliable self-report measure for symptoms of central sensitisation, and later posited as a possible screening instrument. Part A of the CSI questionnaire comprises items relating to symptoms of CSS as identified in a literature search by the original developers of the CSI. Each item is measured on a five-point Likert scale ranging from 0 'never' to 4 'always' (for item content please see Table 1). A cut-off score of 40 on Part A was determined to best distinguish between CSS and nonCSS patients on the original CSI scale [67]. This study used the Dutch translation of the CSI [71] which also uses a cut-off of 40 and has been shown to discriminate well between chronic pain patients and healthy controls, with good internal consistency and test-retest reliability.
All 973 participants included in the present study completed the CSI part A in full.

\section{CSS diagnoses}

Part B of the original CSI contains a list of CSS diagnoses and related disorders. Several health conditions from Part B-fibromyalgia syndrome (FMS), myalgic encephalomyelitis/chronic fatigue syndrome (ME/CFS), irritable bowel syndrome (IBS), restless legs syndrome (RLS), and temporomandibular joint disorder (TMJD)-were included in the 2019 wave of the NAR data collection, with participants able to select them as co-occurring conditions if relevant. The NAR also includes reference to migraine, but within a field entitled "headache/ migraine". It was felt that this category was too broad to accurately identify those participants with migraines versus other types of headache, and therefore this condition was excluded from the analysis. Seven hundred and thirty-three participants completed the section on cooccurring conditions. Participants who indicated one or more of the five included CSS diagnoses were flagged as "diagnosed CSS" with all others, including those who did not answer the questions, flagged as not diagnosed.

\section{Physical health}

Participants were asked to rate their physical health from 0 to 10 with 0 being the poorest health and 10 being good physical health. This question is asked in each wave of the Netherlands Autism Register. All 973 participants had completed the physical health scale.

\section{Sensory sensitivity}

The 35 item Sensory Perception Quotient (SPQ) was developed to assess sensory sensitivity in adults with and without autism, and shows good internal consistency and validity [15, 24, 72]. It is assessed on a four-point Likert scale across five sensory modalities. Items range from 0 'strongly agree' to 3 'strongly disagree'. Lower scores on the SPQ indicate higher sensory sensitivity, and higher scores lower sensitivity. SPQ data was collected in the 2016 wave of the Netherlands Autism Register and we therefore had data from fewer participants for this questionnaire $(n=393)$. Cronbach's $\alpha=0.880$ for the SPQ in this sample.

\section{Autistic traits}

Autistic traits were measured using the 28 item AQ-Short [73], an abridged version of the 50 item Autism Spectrum Quotient or AQ [74]. Items are scored on a fourpoint Likert scale ranging from 1 'definitely agree' to 4 'definitely disagree'. 13 of the 28 items are reverse scored where 'agree' responses are characteristic for autism. This measure has been evaluated in Dutch and English 
samples and was found to have good reliability, sensitivity and specificity $[73,75]$. The $\mathrm{AQ}$ is administered when participants register with the NAR, and therefore although the year completed varied per person, all 973 participants had completed this measure.

\section{Anxiety and depression}

The Hospital Anxiety and Depression Scale or 'HADS' [76], consists of two subscales and is used to identify anxiety (HADS-A) and depression (HADS-D) in non-psychiatric patients. Each subscale contains seven items ranging from 0 to 3 , with 3 indicating greater symptom severity. The dimensional structure of the HADS has been shown to be stable across groups in Dutch samples, with good sensitivity and specificity [77]. HADS data was collected in the 2018 wave of the Netherlands Autism Register and 636 participants had completed the questionnaire in full. Cronbach's $\alpha=0.864$ for the HADS in this sample.

\section{Subjective wellbeing}

Subjective wellbeing was assessed using a composite score from three separate measures, the Subjective Happiness Scale [78], the Satisfaction with Life Scale [79] and the Cantril ladder [80]. Previous psychometric research has shown that combining these measures in a dimensional score of overall wellbeing (range 2-73) is reliable and valid [81]. The Subjective Happiness Scale has four items on a Likert scale from 1 'strongly disagree' to 7 'strongly agree', with higher scores indicating greater happiness. This measure was completed in the 2016 wave of the NAR. The Satisfaction with Life Scale uses the same Likert scale but with five items related to life satisfaction. The Cantril ladder uses an 11-point scale to evaluate general quality of life, with 0 indicating the worst possible life and 10 the best, and this is completed every year of the NAR. In total, 418 participants had completed all three measures and had a subjective wellbeing score.

\section{Statistical analyses}

The CSI has not previously been validated in the autistic population. To establish the factor structure of the Dutch CSI in this sample of autistic adults, an exploratory factor analysis (EFA) was conducted on a random split half of the sample using a promax rotation and weighted least squares extraction method, with confirmatory factor analyses (CFA) using WLSMV estimator performed on the remaining half of the sample, in which we compared the factor structure indicated by the EFA, and the factor structures reported in previous English CSI [70] and Dutch CSI [71] studies in non-autistic samples as well as a bi-factor structure, as proposed by Cuesta-Vargas et al. [82], whereby the covariance between CSI items was accounted for through one general factor and four orthogonal factors. Model fit was interpreted using the Root Mean Square Error of Approximation (RMSEA), Comparative Fit Indicator (CFI), and Tucker-Lewis indicator (TLI). Optimal fit is indicated by values of 0 for the RMSEA and 1 for the CFI and TLI. Criteria for an 'acceptable fit' was an RMSEA $<0.1$, CFI/TFI $>0.9$. Criteria for an 'excellent fit' were RMSEA $<0.06, \mathrm{CFI} /$ TLI $>0.95<1.0[83]$. EFA and CFA analyses were conducted using MPlus version 8.2 [84] and a reliability analysis of the CSI was conducted in SPSS 25.0 [85]. The factor structure of the CSI in men and women was further investigated through multi-group exploratory and confirmatory factor analyses to confirm measurement equivalence; specifically, testing configural, metric and scalar equivalence. Configural equivalence was assumed where the same factor structure was identified as optimal in EFA and CFA. Where this holds it implies that the scale captures the same construct in both groups. Metric and scalar equivalence were tested using multi-group CFA sequentially confirming that factor loadings (metric) and thresholds (scalar) for each item were equivalent. If configural but not metric or scalar equivalence holds then scale scores are not comparable across groups.

Two additional variables were created, one to indicate whether a participant scored above or below the clinical cut-off of 40 on Part A of the CSI (high or low CSI) and the second to indicate whether the participant reported a CSS of FMS, CFS, RLS, IBS and/or TMJD in the physical complaints section. Data were tested for normality and homogeneity of variance. We used independent samples $t$ tests and $\mathrm{Chi}^{2}$ tests to analyse CSS group differences (high versus low CSI, and those with and without a CSS diagnosis), and gender group differences. Where relevant, analyses were corrected for multiple testing using Bonferroni correction. Exploratory analyses were then performed. A four-stage hierarchical regression analysis was used to explore the hypothesis that autistic traits, sensory sensitivity and anxiety might significantly predict CSS symptoms, with age and gender included in stage one as controls, and each construct added in a separate stage to explore their effect on the variance in CSI scores. Path analyses were conducted to investigate whether sensory sensitivity or anxiety might mediate the relationship between autistic traits and CSS symptoms.

\section{Results}

\section{Descriptive statistics}

Out of all 973 participants, 208 (21.4\%) had a formally diagnosed CSS from the list of included conditions; 41 participants indicated having more than one CSS (see Additional file 1: Table S1 for full list). Eighty-seven 
percent of participants with a disclosed CSS diagnosis scored at or above the clinical cut-off of 40 on the CSI; participants with a disclosed CSS scored significantly higher on the CSI than those without, $t(971)=-13.214$, $p<0.001,95 \%$ CI $[-17.083-12.665], d=-1.033 .582$ participants (59.8\% of the sample) scored at or above the clinical cut-off of 40 on the CSI but only $31 \%$ of the 'high CSI' group had a formal CSS diagnosis.

\section{Validation and reliability of the central sensitisation inventory (CSI)}

We analysed the psychometric properties of the CSI since it had not been used before in an autistic sample. Exploratory factor analysis in a randomly selected half of the sample indicated a five-factor solution provided the best explanation of the CSI inter-item covariances (RMSEA 0.051, SRMR 0.037). However, one factor contained only two items and the scree-plot suggested a one-factor solution would be a better fit (see Additional file 2: Figure S1). Confirmatory factor analysis in the other half of the sample considered this five-factor solution (RMSEA $=0.069 ; \mathrm{CFI}=0.931 ; \mathrm{TLI}=0.921$ ), along with a four-factor solution identified in previous studies of the CSI [70] and Dutch CSI[71] (RMSEA $=0.073$; $\mathrm{CFI}=0.921$; $\mathrm{TLI}=0.912$ ), and a bifactor solution proposed by Cuesta-Vargas et al. [82], comprising one general factor and four orthogonal factors (RMSEA $=0.063$; $\mathrm{CFI}=0.945$; $\mathrm{TLI}=0.934$ ) - see Table 1 for factor loadings. Model fit was acceptable for all models but marginally better for the bifactor model. The bifactor model provides support for the use of the CSI as a total score since this model involves the presence of a general factor. This is further supported by the CSI items showing excellent internal consistency (Cronbach's $\alpha=0.907$ with all inter-item correlations highly significant $(p<0.01)$ ). Taken together these results indicate that the CSI total score provides a valid and reliable assessment of the central sensitisation in autistic adults.

Multigroup exploratory factor analysis Configural equivalence was supported by EFA indicating the same number of factors to extract in both genders, and further supported in the CFA sample where the bifactor model was observed to provide optimal fit in both genders. A metric equivalent model, fixing factor loadings to the same values across genders, fit the data significantly

Table 1 Item content and factor loadings $(\lambda)$ of the CSI items

\begin{tabular}{|c|c|c|c|c|c|c|}
\hline \multicolumn{2}{|c|}{ CSI item } & \multirow{2}{*}{$\begin{array}{l}\text { General factor } \\
.560\end{array}$} & \multirow{2}{*}{$\begin{array}{r}\mathrm{F} 1 \boldsymbol{\lambda} \\
.659\end{array}$} & \multirow[t]{2}{*}{$\mathrm{F} 2 \lambda$} & \multirow[t]{2}{*}{$\mathrm{F} 3 \lambda$} & \multirow[t]{2}{*}{$\mathrm{F} 4 \lambda$} \\
\hline 1 & I feel unrefreshed when I wake up in the morning & & & & & \\
\hline 2 & My muscles feel stiff and achy & .705 & -.077 & & & \\
\hline 3 & I have anxiety attacks & .593 & & .189 & & \\
\hline 4 & I grind or clench my teeth & .428 & & & .396 & \\
\hline 5 & I have problems with diarrhoea and/or constipation & .538 & -.018 & & & \\
\hline 6 & I need help in performing my daily activities & .566 & -.110 & & & \\
\hline 7 & I am sensitive to bright lights & 638 & & & .051 & \\
\hline 8 & I get tired very easily when I am physically active & .730 & .041 & & & \\
\hline 9 & I feel pain all over my body & .821 & -.120 & & & \\
\hline 10 & I have headaches & .504 & & & .067 & \\
\hline 11 & I feel discomfort in my bladder and/or burning when I urinate & .522 & & & & 1.756 \\
\hline 12 & I do not sleep well & .557 & .413 & & & \\
\hline 13 & I have difficulty concentrating & .640 & & .628 & & \\
\hline 14 & I have skin problems such as dryness, itchiness, or rashes & .515 & .090 & & & \\
\hline 15 & Stress makes my physical symptoms get worse & 657 & & -.021 & & \\
\hline 16 & I feel sad or depressed & .528 & & .274 & & \\
\hline 17 & I have low energy & .780 & .194 & & & \\
\hline 18 & I have muscle tension in my neck and shoulders & .681 & .078 & & & \\
\hline 19 & I have pain in my jaw & 638 & & & .790 & \\
\hline 20 & Certain smells, such as perfumes, make me feel dizzy and nauseated & 605 & & & .077 & \\
\hline 21 & I have to urinate frequently & .450 & & & & .151 \\
\hline 22 & My legs feel uncomfortable and restless when I am trying to go to sleep at night & .543 & -.011 & & & \\
\hline 23 & I have difficulty remembering things & .490 & & .432 & & \\
\hline 24 & I suffered trauma as a child & .510 & & .173 & & \\
\hline 25 & I have pain in my pelvic area & 661 & & & & .059 \\
\hline
\end{tabular}


Table 2 Group differences between low and high CSI, diagnosed CSS and no diagnosis, men and women

\begin{tabular}{|c|c|c|c|c|c|c|c|}
\hline \multirow[t]{2}{*}{ Measure } & & \multicolumn{6}{|l|}{ Group } \\
\hline & & No CSS & Diagnosed CSS & Low CSI & High CSI & Men & Women \\
\hline \multirow[t]{4}{*}{ CSI } & $N$ & 765 & 208 & 391 & 582 & 410 & 563 \\
\hline & Mean (SD) & $40.4(14.65)$ & $55.3(13.41)$ & $28.4(8.46)$ & $53.8(10.04)$ & $37.1(14.94)$ & 48.3 (14.39) \\
\hline & TTest & \multicolumn{2}{|l|}{$\begin{array}{l}t(971)=-13.214 \\
p<.001^{* *}\end{array}$} & \multicolumn{2}{|l|}{$\begin{array}{l}t(971)=-41.164 \\
p<.001^{* *}\end{array}$} & \multicolumn{2}{|l|}{$\begin{array}{l}t(971)=-11.774 \\
p<.001^{* *}\end{array}$} \\
\hline & d, 95\% Cl [LL UL] & \multicolumn{2}{|c|}{$1.06^{* * *},[-17.08-12.67]$} & \multicolumn{2}{|c|}{$2.74^{* * *},[-26.61-24.19]$} & \multicolumn{2}{|l|}{$0.76^{* *},[-13.04-9.32]$} \\
\hline \multirow[t]{4}{*}{ AQ-short } & $N$ & 765 & 208 & 391 & 582 & 410 & 563 \\
\hline & Mean (SD) & $83.3(10.92)$ & $85.0(10.69)$ & $81.2(11.15)$ & $85.3(10.40)$ & $83.4(11.61)$ & $83.8(10.34)$ \\
\hline & TTest & \multicolumn{2}{|l|}{$\begin{array}{l}t(971)=-2.113 \\
p=.035\end{array}$} & \multicolumn{2}{|l|}{$\begin{array}{l}t(971)=-5.830 \\
p<.001^{* *}\end{array}$} & \multicolumn{2}{|l|}{$\begin{array}{l}t(971)=-.499 \\
p=.618\end{array}$} \\
\hline & $d, 95 \% \mathrm{Cl}[\mathrm{LL} \mathrm{UL}]$ & \multicolumn{2}{|l|}{$N / A,[-3.46-0.13]$} & \multicolumn{2}{|l|}{$0.38^{*},[-5.46-2.71]$} & \multicolumn{2}{|l|}{$N / A,[-1.741 .04]$} \\
\hline \multirow[t]{4}{*}{ SPQ } & $N$ & 313 & 80 & 173 & 220 & 186 & 207 \\
\hline & Mean (SD) & $45.9(15.00)$ & $38.3(13.80)$ & $50.5(14.89)$ & $39.5(13.40)$ & $47.1(15.50)$ & $41.8(14.24)$ \\
\hline & TTest & \multicolumn{2}{|l|}{$\begin{array}{l}t(391)=4.133 \\
p<.001^{* *}\end{array}$} & \multicolumn{2}{|l|}{$\begin{array}{l}t(391)=7.628 \\
p<.001^{* *}\end{array}$} & \multicolumn{2}{|l|}{$\begin{array}{l}t(391)=3.539 \\
p<.001^{* *}\end{array}$} \\
\hline & $d, 95 \%$ Cl [LL UL] & \multicolumn{2}{|l|}{$0.53^{* *},\left[\begin{array}{lll}4.01 & 11.28\end{array}\right]$} & \multicolumn{2}{|l|}{$0.77^{* *},[8.1013 .72]$} & \multicolumn{2}{|l|}{$0.36^{*},[2.368 .26]$} \\
\hline \multirow[t]{4}{*}{ HADS-A } & $N$ & 507 & 129 & 276 & 360 & 276 & 360 \\
\hline & Mean (SD) & $9.2(4.37)$ & $11.7(4.12)$ & $7.3(3.89)$ & $11.5(3.92)$ & $8.5(4.55)$ & $10.5(4.14)$ \\
\hline & TTest & \multicolumn{2}{|l|}{$\begin{array}{l}t(634)=-5.832 \\
p<.001^{* *}\end{array}$} & \multicolumn{2}{|l|}{$\begin{array}{l}t(634)=-13.584 \\
p<.001^{* *}\end{array}$} & \multicolumn{2}{|l|}{$\begin{array}{l}t(634)=-5.809 \\
p<.001^{* *}\end{array}$} \\
\hline & $d, 95 \%$ Cl [LL UL] & \multicolumn{2}{|l|}{$0.58^{* *},[-3.32-1.65]$} & \multicolumn{2}{|l|}{$1.09 * * *,[-4.86-3.63]$} & \multicolumn{2}{|l|}{$0.46^{* *},[-2.69-1.33]$} \\
\hline HADS-D & $N$ & 507 & 129 & 276 & 360 & 276 & 360 \\
\hline & Mean (SD) & $7.0(4.83)$ & $9.2(4.79)$ & $5.5(4.28)$ & $9.0(4.82)$ & $7.1(4.99)$ & $7.7(4.83)$ \\
\hline & TTest & $\begin{array}{l}t(634)=-4.734 \\
p<.001^{* *}\end{array}$ & & $\begin{array}{l}t(634)=-9.411 \\
p<.001^{* *}\end{array}$ & & $\begin{array}{l}t(634)=-1.597 \\
p=.111\end{array}$ & \\
\hline & $d, 95 \%$ Cl [LL UL] & $0.47^{* *},[-3.19-1.32]$ & & $0.76^{* *},[-4.18-2.74]$ & & $N / A,\left[\begin{array}{lll}-1.40 & 0.14\end{array}\right]$ & \\
\hline Physical Health & $N$ & 765 & 208 & 391 & 582 & 410 & 563 \\
\hline & Mean (SD) & $6.6(1.47)$ & $5.2(1.52)$ & $7.1(1.21)$ & $5.8(1.57)$ & $6.6(1.55)$ & $6.1(1.59)$ \\
\hline & TTest & $\begin{array}{l}t(971)=12.121 \\
p<.001^{* *}\end{array}$ & & $\begin{array}{l}t(971)=14.486 \\
p<.001^{* *}\end{array}$ & & $\begin{array}{l}t(971)=4.228 \\
p<.001^{* *}\end{array}$ & \\
\hline & d, 95\% Cl [LL UL] & $0.94^{* * *},\left[\begin{array}{lll}1.17 & 1.63\end{array}\right]$ & & $0.97^{* * *},\left[\begin{array}{lll}1.18 & 1.55\end{array}\right]$ & & 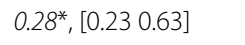 & \\
\hline Subjective Wellbe- & $N$ & 336 & 82 & 185 & 233 & 199 & 219 \\
\hline ing & Mean (SD) & $29.9(8.03)$ & $25.6(7.39)$ & $32.6(7.33)$ & $26.2(7.53)$ & $30.4(8.53)$ & $27.8(7.45)$ \\
\hline & TTest & $\begin{array}{l}t(416)=4.362 \\
p<.001^{* *}\end{array}$ & & $\begin{array}{l}t(416)=8.655 \\
p<.001^{* *}\end{array}$ & & $\begin{array}{l}t(416)=3.289 \\
p=.001^{*}\end{array}$ & \\
\hline & $d, 95 \%$ Cl [LL UL] & $0.55^{* *},[2.336 .16]$ & & 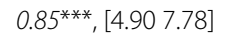 & & $0.32^{*},[1.034 .11]$ & \\
\hline
\end{tabular}

Bonferroni corrected $p$ value $=.002 .{ }^{*} p<.002 ;{ }^{* *} p<.001$. Effect size $d{ }^{*}$ small effect; ${ }^{* *}$ medium; ${ }^{* * *}$ large

CSI, Central Sensitization Inventory; SPQ, Sensory Perception Quotient; AQ-Short, Autism Quotient-Short; HADS-A, Hospital Anxiety and Depression Scale-Anxiety; HADS-D, Hospital Anxiety and Depression Scale-Depression

worse than a configural model, where loadings were allowed to differ $\left(\chi^{2}(24)=37.7, p=0.038\right)$. A partial metric equivalence model, fixing factor loadings to the same values except for items 11 and 16, did not fit significantly worse $\left(\chi^{2}(22)=24.9, p=0.303\right)$. A scalar equivalence model fixing thresholds to the same values did not fit worse than the partial-matric equivalence model $\left(x^{2}(24)=37.7, p=0.038\right)$. Taken together this indicates that the CSI captures the same construct in both men and women but there is some indication of differential item functioning, which may limit the ability to compare scores across genders.

\section{Group differences}

Assumptions of independence and normality were tested, where appropriate, with histograms and Shapiro-Wilk tests. Homogeneity was examined using Levene's Tests. Group differences were calculated using independent $t$-tests. In the diagnosed CSS versus no CSS groups, CSI scores were significantly higher and physical health 
Table 3 Correlation matrix for regression $(n=359)$

\begin{tabular}{lcccccc}
\hline & CSI & Gender & Age & AQ & Anxiety & SPQ \\
\hline CSI & 1.00 & $.349^{* *}$ & 0.05 & $.250^{* *}$ & $.629^{* *}$ & $-.460^{* *}$ \\
Gender & $.349^{* *}$ & 1.00 & $-.261^{* *}$ & 0.02 & $.246^{* *}$ & $-.185^{* *}$ \\
Age & 0.05 & $-.261^{* *}$ & 1.00 & 0.09 & 0.00 & 0.04 \\
AQ & $.250^{* *}$ & 0.02 & 0.09 & 1.00 & $.243^{* *}$ & $-.250^{* *}$ \\
Anxiety & $.629^{* *}$ & $.246^{* *}$ & 0.00 & $.243^{* *}$ & 1.00 & $-.311^{* *}$ \\
SPQ & $-.460^{* *}$ & $-.185^{* *}$ & 0.04 & $-.250^{* *}$ & $-.311^{* *}$ & 1.00 \\
\hline
\end{tabular}

$p$ value $=.05 ;{ }^{*} p<.01 ;{ }^{* *} p<.001{ }^{* *}$

Table 4 Hierarchical regression analysis $(n=359)$

\begin{tabular}{|c|c|c|c|c|c|c|c|c|c|}
\hline & \multicolumn{3}{|c|}{ Stage one } & \multicolumn{3}{|c|}{ Stage two } & \multicolumn{3}{|c|}{ Stage three } \\
\hline & Beta & $t$ & $p$ & Beta & $t$ & $p$ & Beta & $t$ & $p$ \\
\hline (Constant) & & 7.765 & $<.001^{* * *}$ & & 0.090 & 0.928 & & 3.723 & $<.001^{* * *}$ \\
\hline Gender & 0.388 & 7.628 & $<.001^{* * *}$ & 0.377 & 7.633 & $<.001^{* * *}$ & 0.208 & 5.211 & $<.001^{* * *}$ \\
\hline Age & 0.148 & 2.912 & $.004^{* *}$ & 0.124 & 2.499 & $0.013^{*}$ & 0.106 & 2.747 & $0.006^{* *}$ \\
\hline AQ score & & & & 0.231 & 4.819 & $<.001^{* * *}$ & 0.052 & 1.340 & 0.181 \\
\hline Anxiety & & & & & & & 0.483 & 11.884 & $<.001^{* * *}$ \\
\hline SPQ score & & & & & & & -0.263 & -6.565 & $<.001^{* * *}$ \\
\hline
\end{tabular}

$R^{2}=.142$ for Model 1: $\Delta R^{2}=.053$ for Model $2(p<.001): \Delta R^{2}=.320$ for Model $3(p<.001) .{ }^{*} p<.05 ;{ }^{* *} p<.01 ;{ }^{* * *} p<.001$

ratings significantly lower, as expected (Table 2). The diagnosed CSS group also reported significantly lower SPQ scores, indicating greater sensory sensitivity. Participants with a CSS reported significantly more anxiety and depression, and lower subjective wellbeing, than those without a CSS. There was no significant group difference in autistic traits. As some measures were completed in different waves of the NAR and/or some participants had not completed them, the sample sizes differed across measures.

Gender differences were significant for CSI, physical health, SPQ, anxiety and subjective wellbeing, with women obtaining more severe scores for each of these instruments. Chi square tests of independence were used to analyse the relationship between gender, CSS diagnosis, and CSI score group (see Table 2). Women were significantly over-represented in both the diagnosed CSS group, $X^{2}(2, N=973)=33.68, p<0.001$ and the High CSI group, $X^{2}(2, N=973)=89.0, p<0.001$.

\section{Exploratory analyses}

The following analyses were undertaken on an exploratory basis, to provide future research directions.

\section{Hierarchical regression and path analysis}

The data was tested to ensure relevant assumptions were met. Our sample size was considered adequate. Some predictor variables were correlated with each other (see
Table 3) however multicollinearity tests indicated that this was not a concern for the regression analysis, with tolerance ranging from 0.832 (anxiety) to 0.919 (age) and VIFs ranging from 1.088 (age) to 1.201 (anxiety). The data also met the assumption of independent errors (DurbinWatson value $=1.832$ ). Histograms and scatterplots were utilised to ascertain that the assumptions of normality, heteroscedasticity and linearity were met.

The relationships between the main variables were analysed using a four-stage hierarchical multiple regression with CSI score as the dependent variable. Stage one included age and gender, stage two added autistic traits (AQ), stage three sensory sensitivity (SPQ) and stage four anxiety (HADS-A) (Table 4).

Stage one of the regression analysis showed that gender and age were both significantly associated with CSS symptoms and accounted for $14.2 \%$ of the variability in CSI scores. Stage two accounted for $18.8 \%$ of the variability in CSI scores and contributed significantly to the regression model, $F(3,355)=28.67, p<0.001$, with AQ scores explaining $5.3 \%$ additional variance in CSI scores. Sensory sensitivity contributed to a further $12.6 \%$ of the variance $(F(4,354)=41.92, p<0.001)$ and anxiety to $19.4 \%$ of the variance $(F(5,353)=75.09, p<0.001)$. In total the model accounted for $50.9 \%$ of the variance in CSI scores. Level of autism traits (AQ) was not a significant predictor when anxiety and sensory sensitivity were included. 


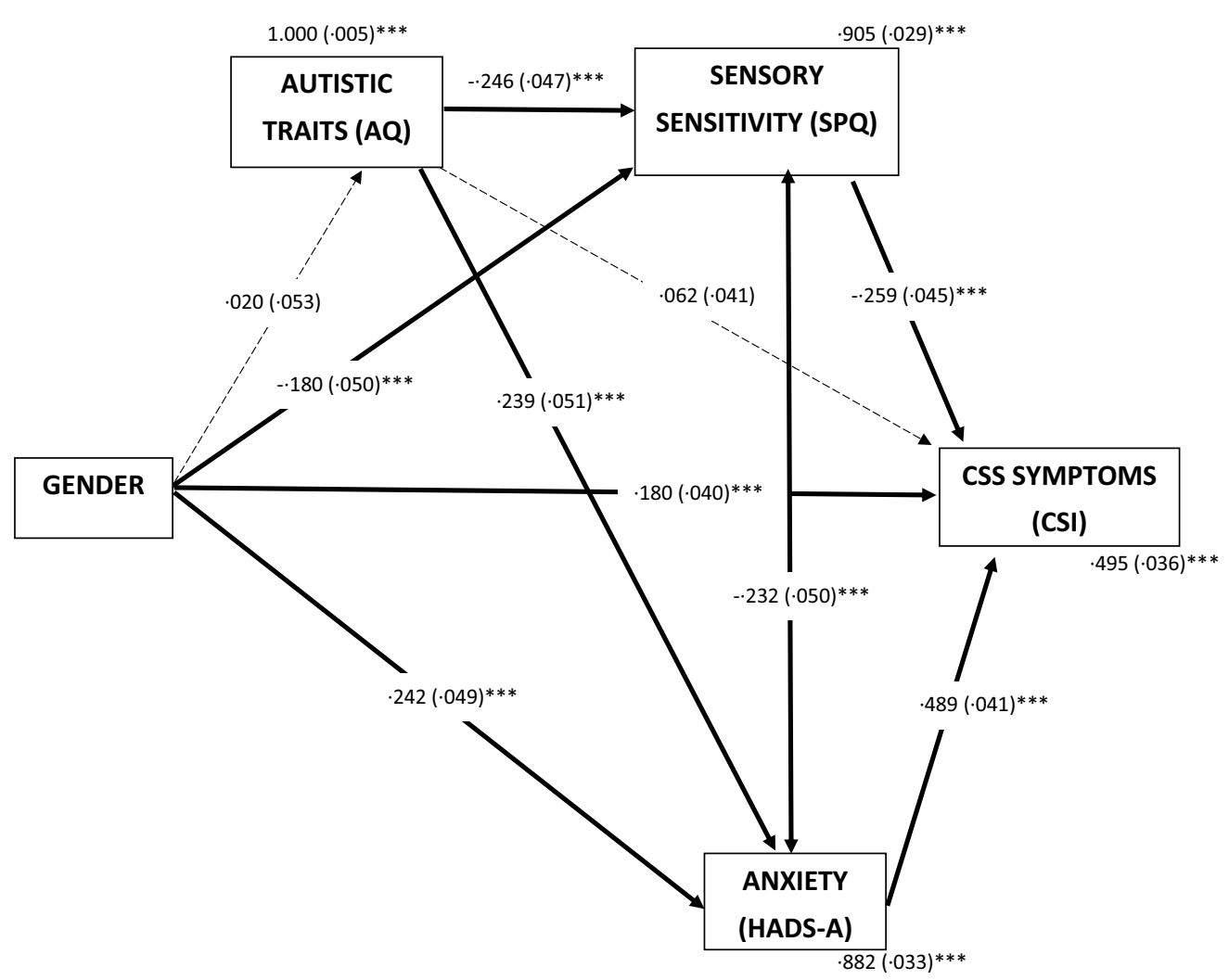

Fig. 1 Mediation model of CSS symptoms in autistic adults. Standardized path coefficients (S.E), covariates and residual variance shown. ${ }^{*} p<.05$; ${ }^{* *} p<.01$; ${ }^{* *} p<.001$

To explore these associations further two path models were performed. Path model one included gender as a predictor variable, sensory sensitivity (SPQ), autistic traits (AQ) and anxiety (HADS-A) as mediator variables, and CSS symptoms (CSI) as an outcome variable (see Fig. 1). The rationale for this approach was that gender is usually established earlier in life, whereas CSS symptoms are more likely to manifest later on. Likewise, autistic traits and sensory sensitivity are both usually present from infancy, and therefore were presented earlier in the model. In this analysis, gender significantly predicted sensory sensitivity $(p<0.001)$, anxiety $(p<0.001)$, and CSS symptoms $(p<0.001)$. Autistic traits significantly predicted both sensory sensitivity $(p<0.001)$ and anxiety $(p<0.001)$. Sensory sensitivity significantly predicted CSI scores $(p<0.001)$ as did anxiety $(p<0.001)$, but autistic traits did not $(p=0.127)$. Anxiety, sensory sensitivity, and gender together accounted for $50.5 \%$ of the variance in CSI scores, $R^{2}=0.505$. The only indirect effect that was non-significant was that of gender on CSS symptoms via autistic traits.

Path model two was performed in which the position of autistic traits and CSS symptoms were reversed, i.e. with gender as a predictor variable, sensory sensitivity (SPQ), CSS symptoms (CSI) and anxiety (HADS-A) as mediator variables, and autistic traits (AQ) as an outcome variable (see Fig. 2). This was based on helpful recommendations from reviewers, given the issues with interpretation of path-analyses in cross-sectional data. In this analysis, gender significantly predicted CSS symptoms $(p<0.001)$. CSS symptoms significantly predicted both sensory sensitivity $(p<0.001)$ and anxiety $(p<0.001)$. Sensory sensitivity significantly predicted autistic traits $(p<0.01)$ as did anxiety $(p<0.05)$, but CSS symptoms did not $(p=0.120)$. Anxiety, sensory sensitivity, and gender together accounted for $10.3 \%$ of the variance in autistic traits, $R^{2}=0.103$. There were no significant indirect effects. Together these two models indicated that differences in CSS symptoms between men and women are likely explained by differences in sensory sensitivity and anxiety, rather than by degree of autistic traits; whereas differences in degree of autistic traits are not directly related to gender. 


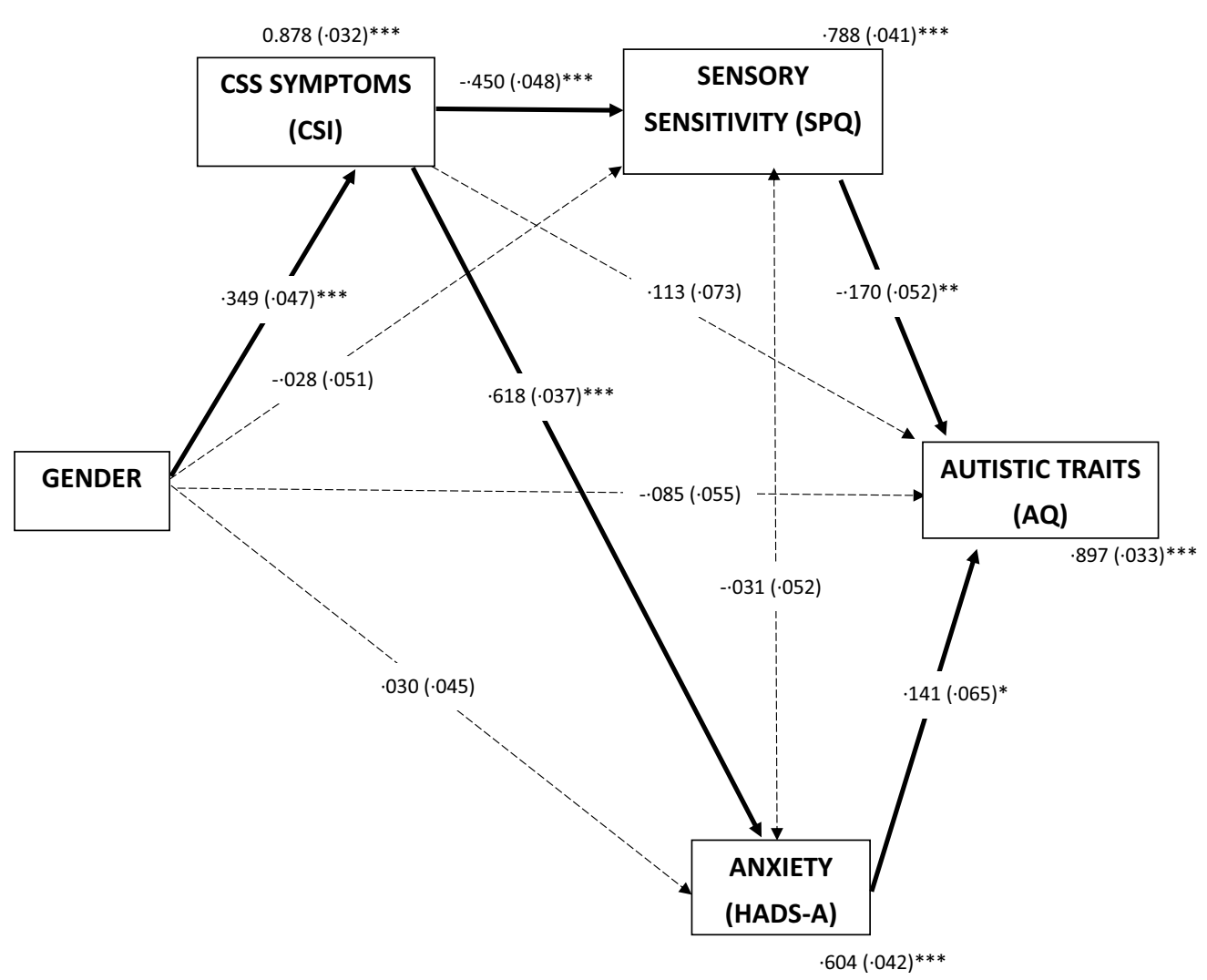

Fig. 2 Alternative mediation model of CSS symptoms in autistic adults. Standardized path coefficients (S.E), covariates and residual variance shown. ${ }^{*} p<.05 ;{ }^{* *} p<.01 ;{ }^{* * *} p<.001$

\section{Discussion}

This is the first study, to our knowledge, that directly considers an association between autism, central sensitisation, and CSS. In our large sample of autistic adults, 21\% reported a CSS diagnosis of FMS, ME/CFS, IBS, RLS or TMJD and $60 \%$ scored at or above the clinical cut-off for a CSS on the CSI, suggesting that CSS symptoms are very common in autistic people.

A factor analysis of the CSI [70] was undertaken to test the measure's construct validity in an autistic sample, as previous CSI studies have focussed on chronic pain and control groups $[67,71,82]$. The results supported the bi-factor model [82], and a highly internally consistent scale. Partial-metric equivalence was observed between genders with items 11 "I feel discomfort in my bladder and/or burning when I urinate" and 16 "I feel sad or depressed" identified as functioning differently between men and women. Given that the difference in loadings were relatively small $(<0.2)$, and that two out of 25 items were affected, the impact on the comparability of scores across males and females is likely to be small. It is unclear whether this observation is specific to autistic people or generalises to the population as a whole.
In our sample, the mean CSI score for those with a diagnosed CSS was 55.3, slightly higher than the mean score of 52.4 Neblett et al. [67] found in their study of CSS patients establishing the clinical cut-off of 40 on the CSI. However, the mean CSI score for autistic participants without a diagnosed CSS was 40.6; a score far higher than that of Neblett's control group (30.9) and closer instead to the mean score of 40.9 in Neblett's non-CSS chronic pain patients. This suggests that CSS symptoms such as pain and fatigue are very common in autistic individuals and possibly more prevalent than in the general population.

There are many theoretical reasons why autism and CSS might be linked with each other. Sensory processing differences are a core feature of autism [13] with autistic people reporting greater sensory sensitivity [15] than the general population. People with CSS also experience sensory sensitivity [14] but in this case it is more clearly associated with central sensitisation [5]. Our results demonstrated that autistic people with greater sensory sensitivity also had more CSS symptoms. Whilst it is possible that this is due to an overlap of symptoms or traits between the CSI and the autistic experience, this also fits 
with recent research indicating that generalised or multisensory sensitivity may be a risk factor for developing central sensitisation or chronic pain [86-89].

Our results also showed that, as predicted, higher scores on the CSI were associated with greater sensory sensitivity, greater anxiety and lower subjective wellbeing. Whilst higher scores on the CSI also appeared to be associated with higher autistic traits, the path analysis conducted suggested that sensory sensitivity and anxiety mediated this relationship. This suggests that sensory sensitivity and anxiety may increase vulnerability to CSS, rather than autism per se.

The finding that anxiety acted as a mediator in this model is in line with previous research on pain in autism that identified anxiety as a contributor to pain levels [29, 69]. CSS research also suggests that anxiety may contribute to both the development of central sensitisation and the severity of symptoms [90, 91]. Although we only considered anxiety in our exploratory analyses, existing research suggests that many mental health conditions could affect the incidence of CSS symptoms in autistic people; high anxiety [33], chronic stress [92] and PTSD $[33,93]$ have all been associated with CSS, and are also more common in the autistic community [29, 31, 34, 94] than the general population. Other psychological factors could also be important; for example, some research suggests chronic illness severity might be affected by illness beliefs and coping mechanisms [95] and how these relate to autism has not been explored.

Just as previously reported in the general population $[57,67]$, there were clear gender differences in this study, with women over-represented for both CSS diagnoses and number and severity of CSS symptoms. Women also showed greater sensory sensitivity and reported greater anxiety, depression and lower subjective wellbeing. Previous research into sensory sensitivity in autism has been mixed when considering gender differences $[15,96]$. Recent studies on the SPQ, both on data within the Netherlands Autism Register (of which this dataset is also a subsample) and outside, found that autistic women had higher sensory sensitivity than both autistic men [72] and non-autistic women [24]. Research within the general population also suggests that women may be more sensitive than men across a range of modalities [58, 97], with hormones thought to play a key role [98]. However consideration needs to be given to issues like gender bias [63]. The results of this study suggest that autistic women might be more likely to experience central sensitisation and related CSS than autistic men.

Whilst not a focus of our study, it is also possible that our results could be explained by neuroimmune and genetic differences in the autistic population. Recent research into joint hypermobility, hypermobility spectrum disorders and the Ehlers-Danlos syndromes (EDS) [52, 56, 99-102] as well as mast cell activation syndrome (MCAS) [103, 104] and dysautonomia [105, 106] has suggested that autistic people, and people with ADHD, are over-represented in these conditions. HSD and EDS are also associated with chronic pain, and are often found to co-occur with, or underly, CSS diagnoses [56]. We did not include questions on joint hypermobility in this study, but future research might consider including these conditions.

Whilst our results show quite clearly that autistic people experience a lot of symptoms associated with central sensitisation, how these symptoms translate to CSS diagnoses is more difficult to establish. Firstly, not all conditions considered to be a CSS were included in our analysis; for example, migraine was not included in our list of CSS, and only 733 of the 973 participants that completed CSI Part A also completed the co-occurring conditions section. This means that the number of participants with a diagnosed CSS is likely to be understated in the current sample. We also did not have CSS diagnosis dates available in our data so cannot examine whether autistic people with CSS were diagnosed with CSS before or after their autism diagnosis. This is important because there are many nuanced difficulties that may exist around diagnosis. For example, autistic people are more likely to experience difficulties accessing healthcare [42, $107]$, communicating with clinicians $[108,109]$, and also express pain differently to the general population [29, 110]. There is also a danger of diagnostic overshadowing, where symptoms of CSS may be incorrectly attributed to an existing autism diagnosis; research shows that clinicians are often uninformed about co-occurring conditions in autism [111]. In addition, fatigue may be attributed to autistic masking [112] or burnout [113] by health professionals or the autistic person themselves, when actually it is a sign of an underlying CSS.

Autism diagnostic issues might also explain why an association between autism and central sensitisation has thus far been largely overlooked. Historically, autism has been classified as a social and communication disorder [114], with sensory issues only included in the most recent DSM criteria [115]. An autism diagnosis is still predominantly based on behaviour in childhood, with a considerable gender bias such that women tend to be underdiagnosed [64] or diagnosed later [65]. Increased understanding of the lived experience of autism has improved awareness of the many co-occurring health issues autistic people experience [116] but this is not reflected in the current diagnostic criteria $[115,117]$ or in measures aiming to assess autistic traits, such as the AQ [74], where large dimensions of the autistic experience are excluded [118]. It could be the case that the CSI 
has captured physical features that have always been common in the autistic population, but not recognised because they were not obvious to the external observer.

Clinically, this study has important implications. We found that the relationship between autistic traits and CSS symptoms was fully mediated by anxiety and sensory sensitivity. Autistic people often struggle to access mental health support or occupational therapy, particularly in adulthood $[119,120]$. Our research suggests that increased anxiety and sensory sensitivity could have wider physical health implications, and longitudinal research could explore further whether interventions focussed on these aspects might mitigate the risk of autistic people developing a CSS later in life.

\section{Limitations}

A strength of this study is that these data were reported as part of an ongoing data collection in the NAR volunteer register, with participants not explicitly primed as to the aims of the CSI data collection. Therefore, it is unlikely that these findings are inflated due to selection or attrition bias.

In terms of limitations, firstly, although we were able to include a large sample of autistic participants, we did not have a control or CSS only group. Future research including these groups would add additional power and allow for a greater exploration of the relationships between the main variables in the wider population. Our sample was also predominantly Dutch, with very few reporting to be a member of an ethnic minority. Future studies should try to recruit a more ethnically diverse sample.

Secondly, the variable 'gender' was assessed by asking participants to check one of three boxes (man/woman/ other). Participants could have interpreted this as either 'sex assigned at birth' or as 'gender of identification'. In many cases sex and gender will overlap but we know this will not apply to everyone. Participants indicating their gender as "other" were excluded due to the small sample size and this field was referred to throughout the study as "gender". Since central sensitisation seems to be linked to sex and hormones $[57,98]$ in the research literature, and that autistic individuals are less likely to identify with their assigned sex at birth [121-123], it is important that further research is undertaken in which assigned sex at birth, gender, and hormonal influences are clearly delineated.

Another important limitation involves the wording of the CSI [70]. It is possible that the association between autism and CSS identified in this study relates more to an overlap of traits (particularly sensory sensitivity) than a true co-occurrence. It is also possible that central sensitisation is directly related to sensory sensitivity [86].
Furthermore, whilst the AQ is a widely used and reliable measure [68], its ability to capture the essence of what autism is, and measure this quantitatively, is limited $[118,124]$. Further studies could utilise different illnessspecific instruments and alternative instruments to the CSI and AQ to establish whether a relationship between autistic traits and CSS can be identified in different conditions.

There are many other aspects that may influence a possible association between autism and CSS that we were unable to measure in this study. For example, the SPQ [15] does not measure interoception, but research indicates interoceptive awareness is altered in autistic people [125] and also people with chronic pain [126]. Similarly, we did not include an alexithymia measure in our analyses, however alexithymia has been indicated in chronic pain [127], and is very common in autistic people [128]. Future research on autism and CSS would need to consider these phenomena.

In this study, CSS diagnoses were self-reported and not independently verified. It is possible that participants may have indicated conditions that were not formally clinically diagnosed. Diagnosis of CSS can be particularly difficult, with clinician bias, misdiagnosis and diagnostic inconsistency a continuing problem $[129,130]$. Future studies could recruit via health services or incorporate additional questions to confirm CSS diagnoses. It is also possible that CSS diagnoses were underestimated in this study, partly due to not all participants completing sections on co-occurring conditions, and partly due to not including the 'migraine' diagnosis as this field also included 'headache' (see "Measures" for more details). It is also important to note that the concept of central sensitisation as a unifying underlying feature of CSS, often also referred to as "chronic overlapping pain conditions" (COPCs), is still relatively new, and research is still evolving in terms of which health conditions are considered to come under this umbrella $[46,131]$, therefore conditions that were included as a CSS in this study may change category in the future. Finally, as a cross-sectional study, this research is limited when exploring cause and effect, such as through the regression and path analyses, and any inferences drawn need to be treated with caution. Longitudinal studies may be able to shed more light on how and why autism and CSS might be related.

\section{Conclusions}

In conclusion, in a large sample of autistic adults, $21 \%$ had a diagnosis of at least one CSS included in this study, and the majority experienced symptoms of central sensitisation, with $60 \%$ scoring at or above the clinical cut-off on a widely used screening measure. 
The results suggest that clinicians need to be aware of a possible association between CSS and autism and mindful of the potential risk of misdiagnosis or diagnostic overshadowing. This is particularly true for women, in whom autism is underdiagnosed [64]. Future research could consider whether autism screening in the diagnostic CSS diagnostic process might be appropriate, for example, and consider whether physical symptoms in autism may warrant evaluation for a CSS bearing in mind the high percentage of autistic adults in this sample that experienced CSS symptoms but did not have a CSS diagnosis.

Most importantly, practitioners should recognise that physical health symptoms and co-occurring conditions are common in autistic people, and that these symptoms can be treated to improve overall quality of life.

\section{Abbreviations}

AQ: Autism Spectrum Quotient; CSI: Central Sensitization Inventory; CSS: Central Sensitivity Syndromes; FMS: Fibromyalgia Syndrome; HADS: Hospital Anxiety and Depression Scale; IBS: Irritable Bowel Syndrome; ME/CFS: Myalgic Encephalomyelitis/Chronic Fatigue Syndrome; NAR: Netherlands Autism Register; PTSD: Post-Traumatic Stress Disorder; SPQ: Sensory Perception Quotient; TMJD: Temperomandibular Joint Disorder.

\section{Supplementary Information}

The online version contains supplementary material available at https://doi. org/10.1186/s13229-022-00486-6.

Additional file 1: Table S1. Number of participants per diagnosis (41 participants had more than one diagnosis). Table S2. Fit statistics for exploratory factor analysis (Promax rotation). Table S3. Fit statistics for exploratory factor analysis (bi-geomin rotation ML estimator). Table S4. Fit statistics for confirmatory factor analysis using robust weighted least squares estimator (WLSMV).

Additional file 2: Figure S1. Scree plot for exploratory factor analysis.

\section{Acknowledgements}

We would like to thank the participants of the Netherlands Autism Register for their contribution to this study.

\section{Authors' contributions}

SG proposed the research question and developed the initial research design. SB, AS and RW prepared and administered the NAR questionnaires, and the corresponding data. SG analysed and interpreted the data with support from $\mathrm{RAH}$ and SN and wrote the first draft of the manuscript. All authors read, contributed to, and approved the final manuscript.

\section{Funding}

Sarah Grant is supported by a studentship from the London Interdisciplinary Social Sciences Doctoral Training Partnership (ESRC Grant No. ST11325). The Netherlands Autism Register was financially supported by the NWO (Grant No. Aut.17.006) and the ZonMW (Grant No. 636340005).

\section{Availability of data and materials}

The datasets generated and/or analysed during the current study are available in the Netherlands Autism Register, www.nederland-sautismeregister.nl/engli sh/.

\section{Declarations}

Ethics approval and consent to participate

The protocol of this study was approved by the ethics committee of the VU University Medical Center (approval number 2013/45) and all participants provided written informed consent.

\section{Consent for publication}

Not applicable.

\section{Competing interests}

The authors declare that they have no competing interests.

\section{Author details}

${ }^{1}$ Department of Psychology, Institute of Psychiatry, Psychology and Neuroscience, King's College London, London SE5 8AF, UK. 'Faculty of Behavioural and Movement Sciences, Clinical Developmental Psychology, Vrije Universiteit Amsterdam, Van der Boechorststraat 7, 1081 BT Amsterdam, Netherlands.

Received: 2 June 2021 Accepted: 24 January 2022

Published online: 14 February 2022

References

1. Croen LA, Zerbo O, Qian Y, Massolo ML, Rich S, Sidney S, et al. The health status of adults on the autism spectrum. Autism. 2015;19(7):814-23.

2. Jones KB, Cottle K, Bakian A, Farley M, Bilder D, Coon H, et al. A description of medical conditions in adults with autism spectrum disorder: a follow-up of the 1980s Utah/UCLA autism epidemiologic study. Autism. 2016;20(5):551-61. https://doi.org/10.1177/1362361315594798.

3. Hirvikoski T, Mittendorfer-Rutz E, Boman M, Larsson H, Lichtenstein P, Bölte S. Premature mortality in autism spectrum disorder. Br J Psychiatry. 2016;208(3):232-8. https://doi.org/10.1192/bjp.bp.114.160192.

4. Rydzewska E, Hughes-McCormack LA, Gillberg C, Henderson A, MacIntyre C, Rintoul J, et al. General health of adults with autism spectrum disorders: a whole country population cross-sectional study. Res Autism Spectr Disord. 2019;60:59-66. https://doi.org/10.1016/j.rasd.2019.01. 004.

5. Yunus MB. Central sensitivity syndromes: a new paradigm and group nosology for fibromyalgia and overlapping conditions, and the related issue of disease versus illness. Semin Arthritis Rheum. 2008;37(6):33952. https://doi.org/10.1016/j.semarthrit.2007.09.003.

6. Marques AP, Santo AD, Berssaneti AA, Matsutani LA, Yuan SL. Prevalence of fibromyalgia: literature review update. Rev Bras Reumatol (Engl Ed). 2017;57(4):356-63. https://doi.org/10.1016/j.rbre.2017.01.005.

7. Lim EJ, Ahn YC, Jang ES, Lee SW, Lee SH, Son CG. Systematic review and meta-analysis of the prevalence of chronic fatigue syndrome/myalgic encephalomyelitis (CFS/ME). J Transl Med. 2020;18:100. https://doi.org/ 10.1186/s12967-020-02269-0.

8. Högl B, Kiechl S, Willeit J, Saletu M, Frauscher B, Seppi K, et al. Restless legs syndrome: a community-based study of prevalence, severity, and risk factors. Neurology. 2005;64(11):1920-4. https://doi.org/10.1212/01. WNL.0000163996.64461.A3.

9. National Institute for Health and Care Excellence (NICE). Irritable bowel syndrome in adults: diagnosis and management. Clinical guideline [CG61]. 2018; pp 1-22. https://www.nice.org.uk/guidance/cg61/resou rces/irritable-bowel-syndrome-in-adults-diagnosis-and-managementpdf-975562917829.

10. Sperber AD, Dumitrascu D, Fukudo S, Gerson C, Ghoshal UC, Gwee $\mathrm{KA}$, et al. The global prevalence of IBS in adults remains elusive due to the heterogeneity of studies: a Rome Foundation working team literature review. Gut. 2017;66(6):1075-82. https://doi.org/10.1136/ gutjnl-2015-311240.

11. Plesh O, Adams SH, Gansky SA. Temporomandibular Joint and Muscle Disorder (TMJMD)-type pain and Co-morbid pains in a National US Sample. J Orofac Pain. 2011;25:190.

12. Bigal ME, Liberman JN, Lipton RB. Age-dependent prevalence and clinical features of migraine. Neurology. 2006;67(2):246-51. https://doi.org/ 10.1212/01.wnl.0000225186.76323.69. 
13. Robertson CE, Baron-Cohen S. Sensory perception in autism. Nat Rev Neurosci. 2017;18(11):671. https://doi.org/10.1038/nrn.2017.112.

14. Wilbarger JL, Cook DB. Multisensory hypersensitivity in women with fibromyalgia: implications for well being and intervention. Arch Phys Med Rehabil. 2012;92(4):653-6. https://doi.org/10.1016/j.apmr.2010.10. 029.

15. Tavassoli T, Hoekstra RA, Baron-Cohen S. The Sensory Perception Quotient (SPQ): Development and validation of a new sensory questionnaire for adults with and without autism. Mol Autism. 2014;5(1):29. https://doi.org/10.1186/2040-2392-5-29.

16. Woolf $\mathrm{CJ}$. Central sensitization: implications for the diagnosis and treatment of pain. Pain. 2011;152(3):S2-15. https://doi.org/10.1016/j.pain. 2010.09.030.

17. Geisser ME, Strader Donnell C, Petzke F, Gracely RH, Clauw DJ, Williams DA. Comorbid somatic symptoms and functional status in patients with fibromyalgia and chronic fatigue syndrome: sensory amplification as a common mechanism. Psychosomatics. 2008;49(3):235-42. https://doi. org/10.1176/appi.psy.49.3.235

18. Suhnan AP, Finch PM, Drummond PD. Hyperacusis in chronic pain: neural interactions between the auditory and nociceptive systems. Int J Audiol. 2017;56:801-9. https://doi.org/10.1080/14992027.2017.13463 03.

19. Blau JN, Solomon F. Smell and other sensory disturbances in migraine. J Neurol. 1985;232(5):275-6. https://doi.org/10.1007/BF00313864.

20. Mezhov V, Guymer E, Littlejohn G. Central sensitivity and fibromyalgia. Intern Med J. 2021. https://doi.org/10.1111/IMJ.15430.

21. Harriott AM, Schwedt TJ. Migraine is associated with altered processing of sensory stimuli. Curr Pain Headache Rep. 2014. https://doi.org/10. 1007/s11916-014-0458-8.

22. Ward J. Individual differences in sensory sensitivity: a synthesizing framework and evidence from normal variation and developmental conditions. Cogn Neurosci. 2018;10(3):139-57. https://doi.org/10.1080/ 17588928.2018.1557131.

23. DuBois D, Lymer E, Gibson BE, Desarkar P, Nalder E. Assessing sensory processing dysfunction in adults and adolescents with autism spectrum disorder: a scoping review. Brain Sci. 2017. https://doi.org/10. 3390/brainsci7080108.

24. Taylor E, Holt R, Tavassoli T, Ashwin C, Baron-Cohen S. Revised scored Sensory Perception Quotient reveals sensory hypersensitivity in women with autism. Mol Autism. 2020. https://doi.org/10.1186/ s13229-019-0289-x.

25. Moore DJ. Acute pain experience in individuals with autism spectrum disorders: a review. Autism. 2015;19:387-99. https://doi.org/10.1177/ 1362361314527839 .

26. Fründt O, Grashorn W, Schöttle D, Peiker I, David N, Engel AK, et al. Quantitative sensory testing in adults with autism spectrum disorders. J Autism Dev Disord. 2017;47(4):1183-92. https://doi.org/10.1007/ s10803-017-3041-4.

27. Vaughan S, McGlone F, Poole H, Moore DJ. A quantitative sensory testing approach to pain in autism spectrum disorders. J Autism Dev Disord. 2019. https://doi.org/10.1007/s10803-019-03918-0.

28. Zhang W, Li X, Yao J, Ye Q, Peng W. Abnormalities in pain sensitivity among individuals with autism spectrum disorder: evidence from meta-analysis. Acta Psychol Sin. 2021;53(6):613. https://doi.org/10.3724/ sp.j.1041.2021.00613.

29. Failla MD, Gerdes MB, Williams ZJ, Moore DJ, Cascio CJ. Increased pain sensitivity and pain-related anxiety in individuals with autism. PAIN Rep. 2020:5(6): e861. https://doi.org/10.1097/pr9.0000000000000861.

30. Failla MD, Moana-Filho EJ, Essick GK, Baranek GT, Rogers BP, Cascio CJ. Initially intact neural responses to pain in autism are diminished during sustained pain HHS Public Access. Autism. 2018;22(6):669-83. https:// doi.org/10.1177/1362361317696043

31. Lai M-C. Lombardo, Michael V, Baron-Cohen S. Autism. Lancet. 2013;383(9920):896-910. https://doi.org/10.1016/S0140-6736(13) 61539-1.

32. Midenfjord I, Grinsvall C, Koj P, Carnerup I, Törnblom H, Simrén M. Central sensitization and severity of gastrointestinal symptoms in irritable bowel syndrome, chronic pain syndromes, and inflammatory bowel disease. Neurogastroenterol Motil. 2021. https://doi.org/10.1111/NMO. 14156.
33. Raphael KG, Janal MN, Nayak S, Schwartz JE, Gallagher RM. Psychiatric comorbidities in a community sample of women with fibromyalgia. Pain. 2006;124(1-2):117-25. https://doi.org/10.1016/j.pain.2006.04.004.

34. Kerns CM, Newschaffer CJ, Berkowitz SJ. Traumatic childhood events and autism spectrum disorder. J Autism Dev Disord. 2015:45(11):347586. https://doi.org/10.1007/s10803-015-2392-y.

35. McKernan LC, Johnson BN, Crofford LJ, Lumley MA, Bruehl S, Cheavens JS. Posttraumatic stress symptoms mediate the effects of trauma exposure on clinical indicators of central sensitization in patients with chronic pain. Clin J Pain. 2019;35(5):385. https://doi.org/10.1097/AJP. 0000000000000689

36. Brewster ME, Esposito J. Chronic Illness rejection and discrimination scale: an instrument modification and confirmatory factor analysis. Stigma Health. 2017;2:16-22. https://doi.org/10.1037/sah0000039.

37. Van Alboom M, De Ruddere L, Kindt S, Loeys T, Van Ryckeghem D, Bracke $P$, et al. Well-being and perceived stigma in individuals with rheumatoid arthritis and fibromyalgia: a daily diary study. Clin J Pain. 2021:37(5):349-58. https://doi.org/10.1097/AJP.0000000000000929.

38. Botha M, Frost DM. Extending the minority stress model to understand mental health problems experienced by the autistic population. Soc Ment Health. 2018. https://doi.org/10.1177/2156869318804297.

39. Han E, Scior K, Avramides K, Crane L. A systematic review on autistic people's experiences of stigma and coping strategies. Autism Res. 2021. https://doi.org/10.31219/osf.io/j7nkv.

40. Janevic MR, MCLaughlin SJ, Heapy AA, Thacker C, Piette JD. Racial and socioeconomic disparities in disabling chronic pain: findings from the health and retirement study. J Pain. 2017:18(12):1459-67. https://doi. org/10.1016/j.jpain.2017.07.005.

41. Lorenz T, Brüning CR, Waltz M, Fabri M. Not a stranger to the dark: discrimination against autistic students and employees. Adv Autism. 2021:7(1):60-72. https://doi.org/10.1108/AlA-10-2019-0036.

42. Doherty M, Neilson SD, O'Sullivan JD, Carravallah L, Johnson M, Cullen W, et al. Barriers to healthcare for autistic adults: consequences \& policy implications. A cross-sectional study MedRxiv. 2020. https://doi.org/10. 1101/2020.04.01.20050336v2.

43. Wang XJ, Ebbert JO, Gilman EA, Rosedahl JK, Ramar P, Philpot LM. Central sensitization symptom severity and patient-provider relationships in a community setting. J Prim Care Community Health. 2021. https:// doi.org/10.1177/21501327211031767.

44. Briones-Vozmediano E, Öhman A, Goicolea I, Vives-Cases C." The complaining women": health professionals' perceptions on patients with fibromyalgia in Spain. Disabil Rehabil. 2018:40(14):1679-85. https://doi. org/10.1080/09638288.2017.1306759.

45. Pheby DFH, Araja D, Berkis U, Brenna E, Cullinan J, de Korwin JD, et al. A literature review of gp knowledge and understanding of me/cfs: a report from the socioeconomic working group of the european network on me/cfs (euromene). Medicina. 2021:57(1):1-17. https://doi. org/10.3390/medicina57010007.

46. Williams DA. Phenotypic features of central sensitization. J Appl Biobehav Res. 2018. https://doi.org/10.1111/jabr.12135.

47. Bursch B, Ingman K, Vitti L, Hyman P, Zeltzer LK. Chronic pain in individuals with previously undiagnosed autistic spectrum disorders. J Pain. 2004;5(5):290-5. https://doi.org/10.1016/j.jpain.2004.04.004.

48. Lipsker CW, Bölte S, Hirvikoski T, Lekander M, Holmström L, Wicksell RK. Prevalence of autism traits and attention-deficit hyperactivity disorder symptoms in a clinical sample of children and adolescents with chronic pain. J Pain Res. 2018;11:2827-36. https://doi.org/10.2147/JPR.S177534.

49. Miyamae T, Chiba Y, Kato I, Tani Y, Yamanaka H. Neurodevelopmental disorders associated with juvenile fibromyalgia. Pediatr Int. 2018:60(11):1034-5. https://doi.org/10.1111/ped.13696.

50. Jacobs H, Singhi S, Gladstein J. Medical comorbidities in pediatric headache. Semin Pediatr Neurol. 2016;23(1):60-7. https://doi.org/10.1016/j. spen.2016.02.001.

51. Baeza-Velasco C, Cohen D, Hamonet C, Vlamynck E, Diaz L, Cravero C, et al. Autism, joint hypermobility-related disorders and pain. Front Psychiatry. 2018:9:1-8. https://doi.org/10.3389/fpsyt.2018.00656.

52. Eccles J, Owens A, Harrison N, Grahame R, Critchley H. Joint hypermobility and autonomic hyperactivity: an autonomic and functional neuroimaging study. Lancet. 2016;387:S40. https://doi.org/10.1016/ S0140-6736(16)00427-X. 
53. Casanova E, Sharp J, Edelson S, Kelly D, Casanova M. A cohort study comparing women with autism spectrum disorder with and without generalized joint hypermobility. Behav Sci (Basel). 2018;8(3):35. https:// doi.org/10.3390/bs8030035.

54. Castori M, Celletti C, Camerota F, Grammatico P. Chronic fatigue syndrome is commonly diagnosed in patients with Ehlers-Danlos syndrome hypermobility type/joint hypermobility syndrome. Clin Exp Rheumatol Suppl. 2011;29(3):597-8.

55. Zhang W, Windsor K, Jones R, Taunton DO. Hypermobile type EhlersDanlos syndrome associated with hypogammaglobulinemia and fibromyalgia: a case-based review on new classification, diagnosis, and multidisciplinary management. Clin Case Rep. 2019;7(4):680-5. https:// doi.org/10.1002/ccr3.2070.

56. Eccles JA, Thompson B, Themelis K, Amato ML, Stocks R, Pound A, et al. Beyond bones: the relevance of variants of connective tissue (hypermobility) to fibromyalgia, ME/CFS and controversies surrounding diagnostic classification: an observational study. Clin Med J R Coll Phys Lond. 2021;21(1):53-8. https://doi.org/10.7861/CLINMED.2020-0743.

57. Lawrence RC, Felson DT, Helmick CG, Arnold LM, Choi H, Deyo RA, et al. Estimates of the prevalence of arthritis and other rheumatic conditions in the United States: part II. Arthritis Rheum. 2008;58(1):26-35. https:// doi.org/10.1002/art.23176.

58. Fillingim RB. Sex, gender and pain. In: Principles of gender-specific medicine. 3rd edition. 2017. p. 481-96.

59. Dao TTT, LeResche L. Gender differences in Pain. J Orofac Pain 2000;14(3):169-84.

60. Smith MT, Remeniuk B, Finan PH, Speed TJ, Tompkins DA, Robinson M, et al. Sex differences in measures of central sensitization and pain sensitivity to experimental sleep disruption: implications for sex differences in chronic pain. Sleep. 2019;42(2):1-15. https://doi.org/10.1093/sleep/ zsy209.

61. Quiton RL, Greenspan JD. Sex differences in endogenous pain modulation by distracting and painful conditioning stimulation. Pain. 2007;132(Suppl 1):S134-49. https://doi.org/10.1016/j.pain.2007.09.001.

62. Samulowitz A, Gremyr I, Eriksson E, Hensing G. "Brave men" and "emotional women": a theory-guided literature review on gender bias in health care and gendered norms towards patients with chronic pain. Pain Res Manag. 2018;2018:1-14. https://doi.org/10.1155/2018/63586 24.

63. Zhang L, Losin EAR, Ashar YK, Koban L, Wager TD. Gender biases in estimation of others' pain. J Pain. 2021;22(9):1048-59. https://doi.org/10. 1016/j.jpain.2021.03.001.

64. Loomes R, Hull L, Mandy WPL. What is the male-to-female ratio in autism spectrum disorder? A systematic review and meta-analysis. J Am Acad Child Adolesc Psychiatry. 2017;56:466-74. https://doi.org/10 1016/j.jaac.2017.03.013.

65. Begeer S, Mandell D, Wijnker-Holmes B, Venderbosch S, Rem D, Stekelenburg F, et al. Sex differences in the timing of identification among children and adults with autism spectrum disorders. J Autism Dev Disord. 2013;43(5):1151-6.

66. Weir E, Allison C, Warrier V, Baron-Cohen S. Increased prevalence of non-communicable physical health conditions among autistic adults. Autism. 2020. https://doi.org/10.1177/1362361320953652.

67. Neblett R, Cohen H, Choi Y, Hartzell MM, Williams M, Mayer TG, et al. The Central Sensitization Inventory (CSI): establishing clinically significant values for identifying central sensitivity syndromes in an outpatient chronic pain sample. J Pain. 2014;14(5):438-45. https://doi.org/10. 1016/j.jpain.2012.11.012.

68. Ruzich E, Allison C, Smith P, Watson P, Auyeung B, Ring H, et al. Measuring autistic traits in the general population: a systematic review of the Autism-Spectrum Quotient (AQ) in a nonclinical population sample of 6,900 typical adult males and females. Mol Autism. 2015;6(2):1-12.

69. Sullivan JC, Miller LJ, Nielsen DM, Schoen SA. The presence of migraines and its association with sensory hyperreactivity and anxiety symptomatology in children with autism spectrum disorder. Autism. 2014;18(6):743-7. https://doi.org/10.1177/1362361313489377.

70. Mayer TG, Neblett R, Cohen H, Howard KJ, Choi YH, Williams MJ, et al. The development and psychometric validation of the central sensitization inventory. Pain Pract. 2012;12(4):276-85. https://doi.org/10.1111/j. 1533-2500.2011.00493.x.
71. Kregel J, Vuijk PJ, Descheemaeker F, Keizer D, Van Der Noord R, Nijs J, et al. The Dutch Central Sensitization Inventory (CSI): factor analysis, discriminative power, and test-retest reliability. Clin J Pain. 2016;32(7):62430. https://doi.org/10.1097/AJP.0000000000000306.

72. Weiland RF, Polderman TJC, Hoekstra RA, Smit DJA, Begeer S. The Dutch Sensory Perception Quotient-Short in adults with and without autism. Autism. 2020;24(8):2071-80. https://doi.org/10.1177/1362361320 942085.

73. Hoekstra RA, Vinkhuyzen AA, Wheelwright S, Bartels M, Boomsma $\mathrm{Dl}$, et al. The construction and validation of an abridged version of the autism-spectrum quotient (AQ-short). J Autism Dev Disord. 2011;41(5):589-96. https://doi.org/10.1007/s10803-010-1073-0.

74. Baron-Cohen S, Wheelwright S, Skinner R, Martin J, Clubley E. The Autism-Spectrum Quotient (AQ): evidence from asperger syndrome/ high-functioning autism, malesand females, scientists and mathematicians. J Autism Dev Disord. 2001;31:5-17. https://doi.org/10.1023/A 1005653411471.

75. Murray AL, McKenzie K, Kuenssberg R, Booth T. Do the autism spectrum quotient (AQ) and autism spectrum quotient short form (AQ-S) primarily reflect general ASD traits or specific ASD traits? A bi-factor analysis Assessment. 2017;24(4):444-57. https://doi.org/10.1177/1073191115 611230.

76. Zigmond AS, Snaith R. Hospital anxiety and depression scale. Acta Psychiatr Scand. 1983;67(6):361-70. https://doi.org/10.1111/j.1600-0447. 1983.tb09716.x

77. Spinhoven PH, Ormel J, Sloekers PPA, Kempen GIJM, Speckens AEM, Van Hemert AM. A validation study of the Hospital Anxiety and Depression Scale (HADS) in different groups of Dutch subjects. Psychol Med. 1997. https://doi.org/10.1017/S0033291796004382.

78. Lyubomirsky S, Lepper HS. A measure of subjective happiness: preliminary reliability and construct validation. Soc Indic Res. 1999;46:137-55. https://doi.org/10.1023/A:1006824100041.

79. Diener ED, Emmons RA, Sem RJL, Griffin S. The satisfaction with life scale. J Pers Assess. 1985;49(1):71-5. https://doi.org/10.1207/s15327752 pa4901 13.

80. Cantril H. Pattern of human concerns. New Brunswick: Rutgers University Press; 1965

81. Grove R, Hoekstra RA, Wierda M, Begeer S. Special interests and subjective wellbeing in autistic adults. Autism Res. 2018;11(5):766-75. https:// doi.org/10.1002/aur.1931.

82. Cuesta-Vargas Al, Neblett R, Chiarotto A, Kregel J, Nijs J, van Wilgen CP, et al. Dimensionality and reliability of the central sensitization inventory in a pooled multicountry sample. J Pain. 2018;19(3):317-29. https://doi. org/10.1016/j.jpain.2017.11.006.

83. Gunzler DD, Morris N. A tutorial on structural equation modeling for analysis of overlapping symptoms in co-occurring conditions using MPlus. Stat Med. 2015;34(24):3246-80. https://doi.org/10.1002/sim. 6541.

84. Muthén LK, Muthén BO. Mplus User's Guide. 7th ed. Los Angeles: Muthén \& Muthén.

85. IBM SPSS Statistics for Windows, Version 25.0. Armonk: IBM Corp. 2017.

86. Bar-Shalita T, Granovsky Y, Parush S, Weissman-Fogel I. Sensory modulation disorder (SMD) and pain: a new perspective. Front Integr Neurosci. 2019;13:1-10. https://doi.org/10.3389/fnint.2019.00027.

87. Wang D, Merkle SL, Lee JE, Sluka KA, Rakel B, Graven-Nielsen T, et al. Multisensory sensitivity is related to deep-tissue but not cutaneous pain sensitivity in healthy individuals. J Pain Res. 2020;13:2493-508. https://doi.org/10.2147/JPR.S267972.

88. Wang D, Casares S, Eilers K, Hitchcock S, Iverson R, Lahn E, et al. Assessing multisensory sensitivity across scales: using the resulting core factors to create the multisensory amplification scale. J Pain. 2021. https:// doi.org/10.1016/j.jpain.2021.07.013.

89. Schrepf A, Williams DA, Gallop R, Naliboff BD, Basu N, Kaplan C, et al. Sensory sensitivity and symptom severity represent unique dimensions of chronic pain: a MAPP Research Network study. Pain. 2018;159(10):2002-11. https://doi.org/10.1097/j.pain.0000000000 001299.

90. Clark JR, Nijs J, Yeowell G, Holmes P, Goodwin PC. Trait sensitivity, anxiety, and personality are predictive of central sensitization symptoms in patients with chronic low back pain. Pain Pract. 2019;19(8):800-10. https://doi.org/10.1111/papr.12809. 
91. Keogh E, Birkby J. The effect of anxiety sensitivity and gender on the experience of pain. Cogn Emot. 1999;13(6):813-29. https://doi.org/10. 1080/026999399379096.

92. Nijhof SL, Rutten JM, Uiterwaal CS, Bleijenberg G, Kimpen JL, van de Putte EM. The role of hypocortisolism in chronic fatigue syndrome. Psychoneuroendocrinology. 2014;42:199-206. https://doi.org/10.1016/j. psyneuen.2014.01.017.

93. Åkerblom S, Perrin S, Rivano Fischer M, McCracken LM. The impact of PTSD on functioning in patients seeking treatment for chronic pain and validation of the posttraumatic diagnostic scale. Int J Behav Med. 2017;24(2):249-59. https://doi.org/10.1007/s12529-017-9641-8.

94. Curin JM, Terzić J, Petković ZB, Zekan L, Terzić IM, Šušnjara IM. Lower cortisol and higher ACTH levels in individuals with autism. J Autism Dev Disord. 2003;33(4):443-8. https://doi.org/10.1023/A:1025019030121.

95. Moss-Morris R, Weinman J, Petrie K, Horne R, Cameron L, Buick D. The revised IIIness Perception Questionnaire (IPQ-R). Psychol Health 2002;17(1):1-16. https://doi.org/10.1080/08870440290001494.

96. Robertson AE, Simmons DR. The relationship between sensory sensitivity and autistic traits in the general population. J Autism Dev Disord. 2013:43(4):775-84. https://doi.org/10.1007/s10803-012-1608-7.

97. Dalton P, Doolittle N, Breslin PAS. Gender-specific induction of enhanced sensitivity to odors. Nat Neurosci. 2002;5(3):199-200. https:// doi.org/10.1038/nn803.

98. Farage MA, Osborn TW, MacLean AB. Cognitive, sensory, and emotional changes associated with the menstrual cycle: a review. Arch Gynecol Obstet. 2008;278:299-307. https://doi.org/10.1007/s00404-008-0708-2.

99. Eccles JA, Beacher FDC, Gray MA, Jones CL, Minati L, Harrison NA, et al. Brain structure and joint hypermobility: relevance to the expression of psychiatric symptoms. Br J Psychiatry. 2012;200(6):508-9. https://doi. org/10.1192/bjp.bp.111.092460.

100. Eccles JA, lodice V, Dowell NG, Owens A, Hughes L, Skipper S, et al. Joint hypermobility and autonomic hyperactivity: relevance to neurodevelopmental disorders. J Neurol Neurosurg Psychiatry. 2014;85(8):e3-e3.

101. Casanova EL, Baeza-velasco C, Buchanan CB, Casanova MF. The relationship between autism and ehlers-danlos syndromes/hypermobility spectrum disorders. J Pers Med. 2020;10(4):260. https://doi.org/10.3390/ jpm10040260.

102. Glans M, Thelin N, Humble MB, Elwin M, Bejerot S. Association between adult attention-deficit hyperactivity disorder and generalised joint hypermobility: a cross-sectional case control comparison. J Psychiatr Res. 2021;143:334-40. https://doi.org/10.1016/j.jpsychires.2021.07.006

103. Theoharides TC, Tsilioni I, Bawazeer M. Mast cells, neuroinflammation and pain in fibromyalgia syndrome. Front Cell Neurosci. 2019;13:1-8. https://doi.org/10.3389/fncel.2019.00353.

104. Theoharides TC, Stewart JM, Panagiotidou S, Melamed I. Mast cells, brain inflammation and autism. Eur J Pharmacol. 2016;778:96-102. https://doi.org/10.1016/j.ejphar.2015.03.086.

105. Staud R. Autonomic dysfunction in fibromyalgia syndrome: postural orthostatic tachycardia. Curr Rheumatol Rep. 2008;10:463-6. https:// doi.org/10.1007/s11926-008-0076-8.

106. Casanova EL, Sharp JL, Edelson SM, Kelly DP, Sokhadze EM, Casanova MF. Immune, autonomic, and endocrine dysregulation in autism and ehlers-danlos syndrome/hypermobility spectrum disorders versus unaffected controls. J ReAttach Ther Dev Divers. 2019;2(2):82-95. https://doi. org/10.26407/2019jrtdd.1.20.

107. Harper G, Smith E, Nicolaidis C, Busuttil V, Green J, Welch J, Buckley C US, April. Autistica action briefing: reasonable adjustments. Autistica 2019 [cited 2019 May 31]; www.autistica.org.uk/AutismStrategy.

108. Milton DEM. On the ontological status of autism: the "double empathy problem." Disabil Soc. 2012;27(6):883-7. https://doi.org/10.1080/09687 599.2012.710008.

109. Nicolaidis C, Raymaker DM, Ashkenazy E, McDonald KE, Dern S, Baggs AEV, et al. "Respect the way i need to communicate with you": healthcare experiences of adults on the autism spectrum. Autism. 2015;19(7):824-31. https://doi.org/10.1177/1362361315576221.

110. Liu J, Chen LL, Shen S, Mao J, Lopes M, Liu S, et al. Challenges in the diagnosis and management of pain in individuals with autism spectrum disorder. Rev J Autism Dev Disord. 2020. https://doi.org/10.1007/ s40489-020-00199-7.

111. Micai M, Ciaramella A, Salvitti T, Fulceri F, Fatta LM, Poustka L, et al. Autistic adult health and professional perceptions of it: evidence from the ASDEU Project. Front Psychiatry. 2021;12:614102. https://doi.org/10. 3389/fpsyt.2021.614102.

112. Pearson A, Rose K. A conceptual analysis of autistic masking: understanding the narrative of stigma and the illusion of choice. Autism Adulthood. 2021;3(1):52-60. https://doi.org/10.1089/aut.2020.0043.

113. Raymaker DM, Teo AR, Steckler NA, Lentz B, Scharer M, Delos Santos A, et al. "Having all of your internal resources exhausted beyond measure and being left with no clean-up crew": Defining autistic burnout. Autism Adulthood. 2020;2(2):132-43. https://doi.org/10.1089/aut.2019. 0079.

114. Fletcher-Watson S, Happé F. Autism: a new introduction to psychological theory and current debates. London: Routledge; 2019.

115. American Psychiatric Association. Diagnostic and statistical manual of mental disorders: DSM-5. 2013.

116. Harper G, Smith E, Croen L, Adams F, Bisson H, Buckley C US. Autistica action briefing: other co-occurring conditions. Autistica. 2019 [cited 2019 May 31]; www.autistica.org.uk/AutismStrategy.

117. Organization WH. WHO | International classification of diseases, 11 th revision (ICD-11).WHO. 2018 [cited 2019 Jun 24]. https://www.who.int/ classifications/icd/en/.

118. English MCW, Gignac GE, Visser TAW, Whitehouse AJO, Enns JT, Maybery MT. The Comprehensive Autistic Trait Inventory (CATI): development and validation of a new measure of autistic traits in the general population. Mol Autism. 2021;12(1):37. https://doi.org/10.1186/ s13229-021-00445-7.

119. Hallett S, Crompton CJ. Too complicated to treat? Autistic people seeking mental health support in Scotland. Autistic Mutual Aid Soc Edinb. 2018;1-22.

120. Camm-Crosbie L, Bradley L, Shaw R, Baron-Cohen S, Cassidy S.'People like me don't get support': autistic adults' experiences of support and treatment for mental health difficulties, self-injury and suicidality. Autism. 2019;23(6):1431-41. https://doi.org/10.1177/1362361318 816053.

121. Dewinter J, Begeer S, Dewinter J, De Graaf H, Begeer S. Sexual orientation, gender identity, and romantic relationships in adolescents and adults with autism spectrum social reciprocity in autism view project quality of life and subjective wellbeing in autism view project sexual orientation, gender identity. J Autism Dev Disord. 2017;47:2927-34. https://doi.org/10.1007/s10803-017-3199-9.

122. Walsh RJ, Krabbendam L, Dewinter J, Begeer S. Brief report: Gender identity differences in autistic adults: associations with perceptual and socio-cognitive profiles. [cited 2020 Feb 3]. https://doi.org/10.1007/ s10803-018-3702-y.

123. Warrier V, Greenberg DM, Weir E, Buckingham C, Smith P, Lai MC, et al. Elevated rates of autism, other neurodevelopmental and psychiatric diagnoses, and autistic traits in transgender and gender-diverse individuals. Nat Commun. 2020. https://doi.org/10.1038/s41467-020-17794-1.

124. Wigham S, Rodgers J, Berney T, Le Couteur A, Ingham B, Parr JR. Psychometric properties of questionnaires and diagnostic measures for autism spectrum disorders in adults: a systematic review. Autism. 2019;23(2):287-305

125. DuBois D, Ameis SH, Lai MC, Casanova MF, Desarkar P. Interoception in autism spectrum disorder: a review. Int J Dev Neurosci. 2016;52:104-11. https://doi.org/10.1016/j.ijdevneu.2016.05.001.

126. Quadt L, Critchley HD, Garfinkel SN. The neurobiology of interoception in health and disease. Ann N Y Acad Sci. 2018;1428:112-28. https://doi. org/10.1111/nyas.13915.

127. Aaron RV, Fisher E, de la Vega R, Lumley MA, Palermo TM. Alexithymia in individuals with chronic pain and its relation to pain intensity, physical interference, depression and anxiety. Pain. 2019;160:1. https://doi.org/ 10.1097/j.pain.0000000000001487.

128. Kinnaird E, Stewart C, Tchanturia K. Investigating alexithymia in autism: a systematic review and meta-analysis. Eur Psychiatry. 2019;55:80-9. https://doi.org/10.1016/j.eurpsy.2018.09.004.

129. Galvez-Sánchez CM, Reyes GA. Diagnostic criteria for fibromyalgia: critical review and future perspectives. J Clin Med. 2020;9(4):16. https://doi. org/10.3390/jcm9041219.

130. Nacul L, Lacerda EM, Kingdon CC, Curran H, Bowman EW. How have selection bias and disease misclassification undermined the validity of myalgic encephalomyelitis/chronic fatigue syndrome studies? J Health 
Psychol. 2019;24(12):1765-9. https://doi.org/10.1177/1359105317 695803.

131. Gatchel RJ, Neblett R. Central sensitization: a brief overview. J App Biobehav Res. 2018;23(2):1-5. https://doi.org/10.1111/jabr.12138.

\section{Publisher's Note}

Springer Nature remains neutral with regard to jurisdictional claims in published maps and institutional affiliations.

- fast, convenient online submission

- thorough peer review by experienced researchers in your field

- rapid publication on acceptance

- support for research data, including large and complex data types

- gold Open Access which fosters wider collaboration and increased citations

- maximum visibility for your research: over $100 \mathrm{M}$ website views per year

At BMC, research is always in progress.

Learn more biomedcentral.com/submissions 